\title{
Seaweed (Ascophyllum nodosum) enriched bread is acceptable to consumers
}

\author{
A. C. Hall, A. C. Fairclough, K. Mahadevan and J. R. Paxman \\ Centre for Food Innovation, Sheffield Hallam University, City Campus, Howard Street, Sheffield S1 1WB, UK
}

High-fibre foods ( $\geq 6 \mathrm{~g}$ dietary fibre/100 g) tend to be less appealing organoleptically than foods with higher energy densities ${ }^{(1)}$. Alginate is a dietary fibre found in brown seaweed species, e.g. Ascophyllum nodosum. It has been shown to have numerous health benefits ${ }^{(2-5)}$. We aimed to determine the acceptability of a seaweed-enriched bread.

We developed bread containing $0 \mathrm{~g}$ (control), $5 \mathrm{~g}, 10 \mathrm{~g}, 15 \mathrm{~g}$ and $20 \mathrm{~g}$ Ascophyllum nodosum (sea greens (SG); Seagreens ${ }^{\circledR}$ Ltd, W. Sussex, UK) in $400 \mathrm{~g}$ loaves. Analysis using a combined SIGMA/Fibertech method showed the $20 \mathrm{~g}$ SG enriched loaf contained $17.8 v$. $13.3 \mathrm{~g} / 100 \mathrm{~g}$ dietary fibre in the control loaf. Seventy-nine untrained sensory panellists (18-65 years, 40 males) assessed the acceptability of the toasted breads topped with scrambled eggs ${ }^{(6)}$. Coded samples were randomly presented and rated overall, and across 5 sensory attributes $^{(7)}$, using visual analogue scales (1-9; extremely unacceptable to extremely acceptable) in FIZZ software (Version 2.10c, Biosystemes, France) in accordance with accepted protocols. A score of 5 was used as a cut-off for lower level acceptability ${ }^{(8)}$. Results were analysed using one-way repeated measures ANOVA with Bonferroni post hoc analyses (SPSS V17.0, SPSS Inc. Chicago, USA).

The control bread was significantly more acceptable than the SG-enriched breads overall and for aftertaste, and significantly more acceptable than all but the $15 \mathrm{~g} \mathrm{SG}$ bread for flavour (see table). Post hoc tests showed no significant differences between any of the enriched breads. Importantly, all bread samples were reported as acceptable overall and for all individual sensory attributes.

\begin{tabular}{|c|c|c|c|c|c|c|c|c|c|c|}
\hline \multirow{2}{*}{$\begin{array}{l}\text { Amount of seagreens } \\
\text { per } 400 \mathrm{~g} \text { loaf }\end{array}$} & \multicolumn{2}{|c|}{$0 \mathrm{~g}$} & \multicolumn{2}{|c|}{$5 \mathrm{~g}$} & \multicolumn{2}{|c|}{$10 \mathrm{~g}$} & \multicolumn{2}{|c|}{$15 \mathrm{~g}$} & \multicolumn{2}{|c|}{$20 \mathrm{~g}$} \\
\hline & Means & SD & Means & SD & Means & SD & Means & SD & Means & $\mathrm{SD}$ \\
\hline Appearance & $6.42^{\mathrm{a}}$ & 1.80 & $6.46^{\mathrm{a}}$ & 1.58 & $6.41^{\mathrm{a}}$ & 1.38 & $6.58^{\mathrm{a}}$ & 1.38 & $6.45^{\mathrm{a}}$ & 1.39 \\
\hline Aroma & $6.38^{\mathrm{a}}$ & 1.55 & $6.14^{\mathrm{a}}$ & 1.45 & $6.06^{\mathrm{a}}$ & 1.53 & $6.30^{\mathrm{a}}$ & 1.55 & $6.09^{\mathrm{a}}$ & 1.44 \\
\hline Flavour* & $6.31^{\mathrm{b}}$ & 1.83 & $5.56^{\mathrm{a}}$ & 1.74 & $5.50^{\mathrm{a}}$ & 1.74 & $5.67^{\mathrm{ab}}$ & 1.65 & $5.52^{\mathrm{a}}$ & 1.75 \\
\hline Aftertaste** & $6.34^{\mathrm{b}}$ & 1.67 & $5.58^{\mathrm{a}}$ & 1.59 & $5.63^{\mathrm{a}}$ & 1.59 & $5.70^{\mathrm{a}}$ & 1.50 & $5.54^{\mathrm{a}}$ & 1.70 \\
\hline Texture & $6.44^{\mathrm{a}}$ & 1.80 & $5.94^{\mathrm{a}}$ & 1.62 & $6.14^{\mathrm{a}}$ & 1.62 & $5.92^{\mathrm{a}}$ & 1.72 & $6.00^{\mathrm{a}}$ & 1.71 \\
\hline Overall Acceptability*** & $6.60^{\mathrm{b}}$ & 1.68 & $5.79^{\mathrm{a}}$ & 1.52 & $5.95^{\mathrm{a}}$ & 1.52 & $5_{.93}{ }^{\mathrm{a}}$ & 1.59 & $5.86^{\mathrm{a}}$ & 1.64 \\
\hline
\end{tabular}

Data are presented as means and standard deviations. Different letters in the same row denote means that are significantly different to one another $(* P=0.008, * * P=0.003$,

$* * * P=0.002)$

For the first time, this study has shown that seaweed-enriched bread, a high-fibre food, is acceptable when up to $20 \mathrm{~g}$ SG are added to a $400 \mathrm{~g}$ loaf. Previous studies have included alginate in drinks ${ }^{(2-3,5)}$ and foods ${ }^{(4,9)}$, and most authors ${ }^{(2-5)}$, but not all ${ }^{(9)}$ have reported beneficial health effects at levels similar to those found in SG-enriched bread. Seaweed presents an attractive option for food manufacturers who are keen to maximise the health-giving potential of their dietary fibre-rich products.

This work was supported by Simon Ranger (Seagreens Health Foundation) with funding from the Weight Management Foundation. With thanks to Paul Ash and Chris Trueman for their assistance.

1. Burton-Freeman B (2000). Dietary fibre and energy regulation. J Nutr 130, 272S-275S.

2. Paxman JR, Richardson JC, Dettmar PW et al. (2008). Daily ingestion of alginate reduces energy intake in free-living subjects. Appetite 53, 713-719.

3. Paxman JR, Richardson JC, Dettmar PW et al. (2008a). Alginate reduces the increased uptake of cholesterol and glucose in overweight male subjects: a pilot study. Nutr Res 28, 501-505.

4. Williams JA, Lai C, Corwin H et al. (2004). Inclusion of guar gum and alginate into a crispy bar improves postprandial glycemia in humans. J Nutr 134, $886-889$.

5. Hoad CL, Rayment P, Spiller RC et al. (2004). In vivo imaging of intragastric gelation and its effect on satiety in humans. J Nutr 134, 2293-2300.

6. FSA/IFR (2002). McCance and Widdowson's The Composition of Foods, 6th summary ed. Cambridge: Royal Society of Chemistry.

7. Meilgaard M, Civille GV \& Carr BT (2006). Sensory Evaluation Techniques, 4th ed. London: CRC Press.

8. Mexis SF, Badeka AV, Riganakos KA et al. (2010). Effect of active and modified atmosphere packaging on quality retention of dark chocolate with hazelnuts. Innovative Food Sci Emerg Technol 11, 177-186.

9. Mattes RD (2007). Effects of a combination fibre system on appetite and energy intake in overweight humans. Physiol Behav 90, 705-711. 